Eye movements and word skipping during reading revisited

Denis Drieghe ${ }^{1}$, Keith Rayner ${ }^{2}$, and Alexander Pollatsek ${ }^{2}$

${ }^{1}$ Ghent University, Belgium

${ }^{2}$ University of Massachusetts at Amherst

Address:

Denis Drieghe

Department of Experimental Psychology

Ghent University

Henri Dunantlaan 2

B-9000 Ghent

Belgium

Tel. $32-92646432$

Fax. 32 - 92646496

e-mail: denis.drieghe@UGent.be

Running Head: Eye movements and word skipping 


\begin{abstract}
Two experiments examined word skipping in reading. In Experiment 1, skipping rates were higher for a preview of a predictable word than for a visually similar nonword, indicating full recognition in parafoveal vision. In Experiment 2, foveal load was manipulated by varying the frequency of the word preceding either a 3-letter target word or a misspelled preview. There was again a higher skipping rate for a correct preview, and a lower skipping rate when there was a high foveal load, but there was no interaction, and the pattern of effects in fixation times was the same as in the skipping data. Experiment 2 also showed significant skipping of nonwords similar to the target word, indicating skipping based on partial information.
\end{abstract}




\section{Eye movements and word skipping during reading revisited}

How long readers look at a word is primarily determined by the ease or difficulty associated with the processing of that word. A very robust finding in research on eye movements in reading is that readers look longer at a low-frequency word than at a high-frequency word (e.g. Inhoff \& Rayner, 1986; Rayner, \& Duffy, 1986; Rayner, Sereno, \& Raney, 1996; Schilling, Rayner, \& Chumbley, 1998, Vitu, 1991). Other variables that also reflect the ease of processing, such as predictability of the word from the preceding context (Balota, Pollatsek, \& Rayner, 1985; Binder, Pollatsek, \& Rayner, 1999; Ehrlich, \& Rayner, 1981, Rayner, \& Well, 1996; Schustack, Ehrlich, \& Rayner, 1987; Zola, 1984) or the age at which the word was acquired (Juhasz \& Rayner, 2003, 2005), have also been shown to affect how long a word is looked at. While some low-level visual factors influence the decision of when to move the eyes, a strong case can be made that the linguistic properties of the words are the main determiners of that decision ${ }^{1}$. The opposite seems to be true for the decision of where to move the eyes: low-level visual factors, such as word length and spacing between words (Rayner, Fischer, \& Pollatsek, 1998), are the most important influences on saccade length and on the landing position in a word. For example, the length of a saccade is influenced by the length of the currently fixated word and the length of the word to the right of fixation (e.g. Blanchard, Pollatsek, \& Rayner, 1989; O'Regan, 1980; Rayner, 1979), and readers tend to make their first fixation about halfway between the beginning and the middle of a word (Deutsch \& Rayner, 1999; McConkie, Kerr, Reddix, \& Zola, 1988; Pollatsek \& Rayner, 1982; Rayner, 1979).

A phenomenon in reading that eludes this convenient when/where dichotomy is word skipping (the phenomenon that readers do not fixate on each word in the text). To be precise, about $30 \%$ of the words in a text do not receive a direct fixation during reading (Rayner, 1998). While word skipping is clearly closer to the question of where to move the eyes, influences of both low-level visual factors and high-level linguistic factors have been shown to affect skipping behavior. One of the most robust findings in word skipping is that short words are skipped more often than long words (Brysbaert \& Vitu, 1998; Drieghe, Brysbaert, Desmet, \& De Baecke, 2004; Rayner,

\footnotetext{
1 The effect of word length on the fixation time on a word is hard to classify in that it almost certainly influences how difficult a word is to identify, but it also is likely to have effects that are related to eye movement control.
} 
1979; Rayner \& McConkie, 1976; Vitu, O’Regan, Inhoff, \& Topolski, 1995). But it has also been shown that words that are predictable from the preceding context are skipped more often than words that are not predictable (Altaribba, Kroll, Sholl, \& Rayner, 1996; Balota, et al., 1985; Drieghe et al., 2004; Ehrlich \& Rayner, 1981; Rayner, Binder, Ashby, \& Pollatsek, 2001; Rayner \& Well, 1996; Schustack, Ehrlich, $\&$ Rayner, 1987) and that high-frequency words are more likely to be skipped than low-frequency words (even when their lengths are matched), especially when the eyes are close to the target word on the preceding fixation (Henderson \& Ferreira, 1993; Radach \& Kempe, 1993; Rayner \& Fischer, 1996; Rayner et al., 1996). So, clearly both visual and lexical/linguistic variables affect whether a word is skipped. But arguably the most convincing piece of evidence that word skipping is not easily placed in the classic when/where dichotomy is that even though predictability has a clear effect on the skipping rates, it has no effect on the position of the landing site in cases where the word is actually fixated (Rayner et al, 2001; Vonk, Radach, \& van Rijn, 2000). This indicates that there is a distinction between the mechanisms that determine the saccade target (which word to fixate) and the ones that determine the actual landing site (where to fixate in the word), a distinction we believe should be present in the architecture of any comprehensive model of eye movements in reading.

Returning to the effects of predictability and frequency on word skipping, these effects clearly show that some words that are skipped have been identified, at least to a certain extent. However, the extent to which a word that is skipped was processed during the prior fixation remains an issue of some debate in the literature (e.g. Radach \& Kennedy, 2004; Rayner \& Juhasz, 2004; Reichle, Rayner, \& Pollatsek, 2003), and views on this matter differ rather dramatically. At one extreme, a word is skipped based on an "educated guess", taking only coarse information about the target word into account (Brysbaert, Drieghe, \& Vitu, 2005; Brysbaert \& Vitu, 1998; Drieghe et al., 2004). At the other extreme, a word is mainly skipped because it was recognized in parafoveal vision on the prior fixation (e.g. Reichle et al., 2003). Thus, while a broad consensus exists among researchers in the field on the determinants of the where/when decision, the debate on word skipping continues. Moreover, the debate is enlivened by data on word skipping that have proven hard to simulate by models that do a fairly good job in simulating fixation duration data (Kliegl, \& Engbert, 2004; Rayner, Ashby, Pollatsek, \& Reichle, 2004). 
Before we turn to the issues on word skipping that the current study will address, we will outline a model of reading which will help to frame these questions. The E-Z Reader model (Reichle, Pollatsek, Fisher, \& Rayner, 1998; Reichle, Rayner, \& Pollatsek, 1999, 2003; Rayner, Reichle, \& Pollatsek, 1998; 2000; 2005; Pollatsek, Reichle, \& Rayner, 2003; 2005) is a quantitative model in which the core assumption is that cognitive processes associated with processing the fixated word serve as the engine behind forward eye movements in reading ${ }^{2}$. Word recognition is considered to be a serial process under the control of an attentional beam, with the word in the attentional beam being the only word that is being processed lexically. In addition, the model posits two phases of word recognition. The termination of the first phase, which could be identified with the identification of the orthographic and phonological forms, cues the oculomotor system to begin programming a saccade to the next word. The termination of the second phase, which entails full lexical identification, causes the attentional beam to shift to the next word. Given the parameters of the model, the shift of the attentional beam usually occurs before the eyes move to the next word, and during the time that the attentional beam is on the next word (but the eyes are still on the previous word), parafoveal processing occurs. This mechanism is how the E-Z Reader model accounts for the fact that information is extracted from the word next to the currently fixated word during reading. This parafoveal preview benefit can be seen most clearly from the fixation time on a word that was presented in parafoveal vision on the prior fixation, as compared to when it was masked in parafoveal vision (e.g. Blanchard, et al., 1989; Morris, Rayner, \& Pollatsek, 1990; Rayner, 1975; Rayner, Well, Pollatsek, \& Bertera, 1982; Schroyens, Vitu, Brysbaert, \& d'Ydewalle, 1999). Moreover, because the model posits that the gap in time between the eye movement signal to fixate the next word and the attention shift decreases as a function of the difficulty of processing the currently fixated word, it predicts that this preview benefit decreases as processing difficulty increases ${ }^{3}$.

\footnotetext{
2 The model is serial in that it posits that only one word is processed at a time, but letters within a word are assumed to be processed in parallel (possibly with the exception of long polymorphemic words).

${ }^{3}$ More precisely, the end of the $1^{\text {st }}$ phase of the word recognition of word ${ }_{n}$ cues the oculomotor system to start programming a saccade to $\operatorname{word}_{n+1}$. The amount of time needed for the programming of a saccade is fairly constant, so the eyes land on the next word following a certain delay after the end of the $1^{\text {st }}$ phase. If word $n$ is difficult, there is a longer $2^{\text {nd }}$ phase of the word recognition processes than for an easy word, hence the shift of the attentional beam, caused by the termination of this $2^{\text {nd }}$ phase, occurs later.
} 
The model primarily predicts skipping by the following mechanism: If (a) the eyes are on $\operatorname{word}_{n}$, (b) the attentional beam has shifted to $\operatorname{word}_{n+1}$, and (c) if the first phase of word identification of word $_{n+1}$ in the parafovea is rapid enough, the programming of the eye movement to word $_{n+1}$ is cancelled and replaced by the programming of an eye movement to $\operatorname{word}_{\mathrm{n}+2}$. (The second phase of the identification of word $_{n+1}$ in the parafovea should usually complete before the eyes move to word $d_{n+2}$.) So, while the attentional beam goes to every word in the text, the eyes do not necessarily fixate each word. In the model, the amount of processing needed to complete the first phase of word recognition is related directly to the frequency and the predictability of the word. In this manner the model can successfully predict the effects of predictability and frequency on word skipping. The model can also account for the word length effect in word skipping because it assumes an inverse relation between the extraction of letter information and the distance of a letter from the center of the visual field. So the further away the eyes are from the target word, the more time will be needed to complete the first phase of the word recognition, and as a consequence of that the slimmer chances will be that the word will be skipped. This mechanism accounts both for the well-documented word length effect in reading (McConkie et al., 1988) as well as the effect of launch site (a word close-by will also be skipped more often independent of word length). What chiefly distinguishes this model from models that embrace a more low-level approach to explain word skipping (Brysbaert et al., 2005; Brysbaert \& Vitu, 1998; Drieghe et al., 2004), is that in order for a word to be skipped, a significant amount of processing of the skipped word needs to have happened: the first phase of word recognition has been completed and the completion of full lexical identification of that word has occurred or is imminent.

One phenomenon that is predicted by the E-Z Reader model is that fixations on a word should be longer when the next word is skipped than when the next word is not skipped (all else being equal). This follows from the model because skipping results from the cancellation of the program to fixate word $_{n+1}$ by the program to fixate $\operatorname{word}_{n+2}$. Thus, a later program replaces an earlier program. In fact, such an inflated fixation duration has been observed in several studies (Pollatsek, Rayner, \& Balota, 1986; Pynte, Kennedy, \& Ducrot, 2004; Rayner et al., 2004), but not in others (Drieghe et al., 2004; Engbert et al., 2002; Radach \& Heller, 2000). As a result, trying to explain this phenomenon has been viewed by some as an important arena for 
understanding word skipping, and eye movements in reading more generally. We will return to this issue below.

A second phenomenon that is not directly related to word skipping but is related to the amount of processing that parafoveal words receive is the so-called parafoveal-on-foveal effect. This effect refers to the possibility that the processing of parafoveal information from a word not only aids later foveal processing and sometimes leads to skipping a word, but that it also can affect the processing time on the prior word (other than by the mechanism discussed in the prior paragraph). This phenomenon has been a primary reason why some researchers have rejected the serial processing assumption of the E-Z Reader model and proposed parallel processing of foveal and parafoveal words. In fact, a number of studies have indicated that the foveal viewing time can be altered by the words presented in the parafovea (e.g. Inhoff, Radach, Starr, \& Greenberg, 2000; Kennedy, 1998; 2000; Kennedy, Pynte, \& Ducrot, 2002; Pynte, et al., 2004; Schroyens, et al., 1999; Starr \& Inhoff, 2004; Underwood, Binns, \& Walker, 2000; Vitu, Brysbaert, \& Lancelin, 2004). However, there are methodological problems associated with some of these studies, as well as failures to obtain consistent effects across experiments. We think a fair summary is that it is clear that an unusual beginning of the $\operatorname{word}_{n+1}$ can produce longer fixations on $\operatorname{word}_{\mathrm{n}}$ (Inhoff, Starr, \& Shindler, 2000; Underwood, et al., 2000), but that it is far less clear that the meaning of $\operatorname{word}_{n+1}$ influences the fixation time on $\operatorname{word}_{\mathrm{n}}$ (for a review see Rayner, White, Kambe, Miller \& Liversedge, 2003). In a recent study, Kennedy and Pynte (2005) used a large corpus of eye movement data and claimed to find further evidence of the meaning of the word to the right of fixation influencing the current fixation (particularly when word $_{n+1}$ was a short word). However, there are problems with corpus analyses in that there is no control over difficulty levels associated with the location in the text from which two consecutive words are culled. However, as we will elaborate below, parafoveal-on-foveal effects are not necessarily inconsistent with a serial processing model such as the E-Z Reader model because the model predicts that not all saccades land on the intended word. In fact, there are abundant data indicating that eye movements, like other motor movements, have variability and usually do not land exactly on their target (McConkie et al., 1988). In particular, it is quite reasonable from the quantitative data accumulated by McConkie et al. and others to conclude that it is not rare for saccades to fall short of the targeted word so that word $_{n}$ is fixated even though word $_{n+1}$ was the intended target and is the 
attended word (see also, Rayner, Warren, Juhasz, \& Liversedge, 2004). Whether E-Z Reader (or a serial model) can predict these effects quantitatively, however, is an open question.

Largely spurred by these two phenomena, several models have appeared that have argued for parallel processing of foveal and parafoveal words, notably SWIFT (Engbert, Longtin, \& Kliegl, 2002) and Glenmore (Reilly \& Radach, 2003). That is, lexical processing in these models is spatially distributed across words and a competition for processing resources between the different words is constantly going on; for example a difficult word will use most of the resources leaving few resources for the processing of the other words. In the SWIFT model for example, lexical processing is distributed over a four-word attentional gradient, and (contrary to the E$\mathrm{Z}$ Reader model), lexical processing is not the engine behind eye movements during reading to the same extent as in the E-Z Reader model. Instead, saccades are initiated after a variable (random) time interval to maintain a preferred mean rate of eye movements. Obviously, such parallel processing models do have the capability of predicting parafoveal-on-foveal effects. Whether they give an adequate explanation of such effects we think is also an open question, as well as whether they can account for when such effects do not occur.

How do these models explain skipping? Again using SWIFT as an example, saccades are directed towards words that have the highest level of excitation, which occurs at intermediate amounts of lexical processing. (That is, the default saccade target is not the following word, as in the E-Z Reader model.) Thus, word $_{n+1}$ will be skipped if word $_{n+2}$ has a higher level of excitation, and the model successfully predicts that this occurs when $\operatorname{word}_{n+1}$ is more frequent, more predictable, and shorter. However, because SWIFT does not assume that the next word is the default saccade target, there is no predicted "cost" in canceling a planned saccade to the next word, as it is the case in the E-Z Reader model. Kliegl and Engbert (2004) attempted to resolve the inconsistency in the literature we discussed earlier on whether there is a cost in skipping on the fixation time on the prior word. In a study using a large corpus (where other factors were controlled post-hoc), they found that fixations before skipped words were shorter before short or highly frequent words and longer before long or low frequency words. However, this issue is complex as assessing this effect depends on essentially correlational analyses. That is, whether the reader skipped a word or not was determined by the reader, so that one never can achieve the same 
amount of stimulus or participant control over the situations in which readers skip and the situations in which they don't, as in for instance fixation times.

The current study examines word skipping using the E-Z Reader model as its focus, as we don't think that the phenomena discussed above are fatal to E-Z Reader's explanation of skipping or other parafoveal phenomena in reading. In particular, we wish to highlight the two major assumptions that E-Z Reader makes to explain word skipping. First, the model states that a word is skipped because it is recognized (processed up though the first stage) on the prior fixation by means of parafoveal processing. Second, it states that some skipping will occur because of saccadic error. However, for now, we will focus on the first mechanism. In particular, there appear to be two prior studies whose results seem somewhat at odds with the assumption that skipping results from a fairly full analysis of the parafoveal word.

The first study (Balota et al., 1985) examined the skipping of misspelled parafoveal words in sentences such as: "Since the wedding was today, the baker rushed the wedding cake to the reception", where the target word (italicized) was quite predictable. This study used the eye-contingent display change paradigm, the boundary paradigm (Rayner, 1975), in which a preview stimulus was replaced by either a predictable target word cake or by an unpredictable target word pies when the reader crossed the invisible boundary located before the target. Of major interest for the present purposes is how often various preview stimuli were skipped when a certain word was fairly predictable. In fact, when the predictable word cake was in the parafovea, it was skipped $11 \%$ of the time, whereas the non-predictable (but sensible) word pies was only skipped $2 \%$ of the time. (A non-word that was visually dissimilar to the predictable word picz and a word that was semantically anomalous in the sentence frame bomb also had low skipping rates.) However, a non-word that was visually similar to the predictable word cahc was skipped $11 \%$ of the time. This study was one of the first to show that a predictable word is skipped more often than an unpredictable word in the same location, and thus that skipping was due to the word that was actually there rather than simply due to guessing that the word was likely to be there. However, there are a few features of this study we would like to address.

First, as noted above, Balota et al. reported no difference between a predictable word (cake) and a non-word preview that was visually similar to the predictable word $(\mathrm{cahc})$. This led them to conclude that the decision to skip the target word was not based on a full analysis of the parafoveal word. This conclusion, 
however, is somewhat at odds with the E-Z Reader model we presented earlier. That is, if a word is skipped because it is almost fully recognized, how can there be no difference at all between a predictable word and a visually similar non-word? However, it is not inconceivable that when a word that is skipped from a far launch site, it is skipped based on coarse information. The system would accommodate for this sub-optimal processing by compensating for it on the fixation after the skipping. This latter assumption would be compatible with the findings of Binder, Pollatsek, and Rayner (1999) who reported that readers often still attend to a word after it is skipped (plausibly when a saccade overshot the target word) and with the data reported by Reichle et al. (1998) that the duration of a fixation after a skip is also inflated. Thus, perhaps this lack of difference in the Balota et al. experiment was because a majority of the skips were from a reasonably distant launch site. Unfortunately, Balota et al. did not report skipping rates as a function of different launch sites.

The first experiment reported here is essentially a replication of the Balota et al. study, but an important difference is that we also examined the skipping data as a function of launch site. In order to create a sensitive test of whether there would be a difference between the predictable word and the visually similar non-word preview at close launch sites, we increased the visual similarity by reducing the difference to a single letter. In addition, there is the question about whether there is a difference between a preview of an unpredictable word (pies) and a preview of a non-word (picz) derived from the unpredictable word that is both visually dissimilar to the predictable word (cake). That is, analogous to the question about the predictable word, does it make a difference in skipping rate that one is a word and one is not? The original Balota et al. data are not diagnostic, because there were likely to have been floor effects. To amend this, the original study was replicated in Experiment 1 but all the words longer than 6 letters were taken out of the stimulus set. Because short words are skipped more often than long words, this should increase the overall skipping rates and thus make floor effects less likely. Finally, we also added an extra condition in which a preview was presented that was an unpronounceable, orthographic illegal non-word. This condition was added to determine whether the visually dissimilar condition constituted the lower boundary of skipping behavior.

Experiment 1 focused on the question of how much processing of a parafoveal word is necessary to modulate skipping. This question was also addressed in 
Experiment 2, but the focus in Experiment 2 was on the question of whether word skipping is modulated by foveal load. Henderson and Ferreira (1990) showed that when foveal load is increased (e.g. a low-frequency word prior to the target word) the parafoveal preview benefit is reduced (see also Kennison \& Clifton, 1995; Schroyens et al., 1999; White, Rayner, \& Liversedge, 2005). Models such as the E-Z Reader model explain this phenomenon by stating that because the processing of the word $n$ takes longer, the time window for parafoveal processing to occur between the arrival of the attentional beam and the actual arrival of the eyes on word $n+1$ will be smaller, hence less processing will have occurred. Because the E-Z Reader model relies heavily on parafoveal processing in explaining skipping behavior, the model would clearly predict that a higher foveal load will be accompanied by a lower skipping rate of the following word. If this is observed, then it would be another piece of data indicating that word skipping is importantly determined by word processing, contrary to other "where to move the eyes" decisions. This is even more so the case since previous research has shown that foveal load has only a small effect on the saccade length originating from the target word (e.g., Rayner, Ashby et al., 2004).

The second study that seemed problematic for the E-Z Reader model's account of word skipping was by White (2004), as she reported finding no effect of foveal load on the skipping of the following word. She used five to six-letter foveal words and four-letter target words (i.e., the words whose skipping rates were assessed). The preview of the target word was either correct or misspelled. While there was a main effect of preview (the correct previews were skipped more often than the incorrect previews), no other significant effects were observed with the exception of an incorrect preview being skipped less often when it was preceded by a low frequency word. These findings can clearly not be accounted for by the mechanisms incorporated in the E-Z Reader model. However, because the overall skipping rates in this study were rather low, the lack of an effect of foveal load could have been due to a lack of power. As a result, we decided to use shorter target words. In Experiment 2, we employed three letter target words (for which the preview was either correct or misspelled) which were preceded by either a high-frequency or a low-frequency five letter word.

\section{EXPERIMENT 1}

The primary question explored in Experiment 1 was whether the findings of Balota et al. (1985), indicating that there is no difference in skipping rate between a 
predictable word and a nonword that was visually similar to it, would still be true if one examined situations in which the prior fixation was close to the target region (i.e., at a close launch site). In addition, to make the test more sensitive, we used shorter stimuli than were used than in the original study to avoid floor effects.

If skipping is merely based on a crude estimate of whether a predictable word was present, then skipping rates should be about the same when the predictable word and a nonword visually similar to it are present in the parafovea and those skipping rates should be higher than the other conditions in which the preview of the target word is orthographically different from the predictable target word. Moreover, if the preview is orthographically different from the target word, then skipping rates should not be affected by whether it is a word or nonword and/or whether the word fits in with the sentence. We expected that this might be the pattern when the launch site is far from the target word region. However, we thought that at close launch sites, there would be a more complete analysis of the preview stimulus, and thus that skipping rates would be at least sensitive to whether the preview was the predictable word or the nonword that was visually similar to it. It was less clear whether skipping rates would be at all influenced by the lexicality or sensibility of the preview if it wasn't a candidate for the predictable word.

\section{METHOD}

Participants. Twenty-four members of the University of Massachusetts community participated in this experiment. All were native speakers of American English and had 20/20 vision or contacts. They were either given extra credit in a Psychology course or paid $\$ 8$ for their participation.

Apparatus. Participants were seated $61 \mathrm{~cm}$ from a 15-inch NEC MultiSync FGE color monitor. All sentences were displayed on a single line with a maximum length of 80 characters. At this distance, 3.8 character positions equaled 1 degree of visual angle. An eye contingent boundary technique was used (Rayner, 1975) in which display changes occurred within $5 \mathrm{~ms}$ of detection of when an invisible "boundary" was crossed; the boundary was between the last letter of the prior word and the space preceding the target word. Eye movements were recorded using a Fourward Technologies Dual Purkinje Eyetracker (Generation V) interfaced with a Pentium computer. Although reading took place binocularly, eye movements were recorded only from the participants' right eye, sampling the eye's position every millisecond. 
Materials. The sentences were selected from the materials used by Balota et al. (1985). In the original study, 96 sentence frames were used. Two separate norming procedures were used to assess the predictability of the predictable and unpredictable (but not anomalous) words. In the first procedure, 20 participants were presented with the sentences up to and including the target word. Their task was to indicate, on a 5point scale, how well the base word fit into the sentence $(1=$ the word did not fit very well; $5=$ the word fit very well). The mean ratings for the predictable and unpredictable words were 4.47 and 2.32, respectively. In the second procedure, 20 participants who did not participate in the first norming study, were given the sentence frame up to, but not including, the target word and were asked to generate the next word in the sentence. The predictable words were generated $64 \%$ of the time, whereas the unpredictable words were generated less than $1 \%$ of the time. Target words ranged in length from 4 to 8 characters, with a mean of 5.2 characters. For the current experiment we removed the 7 and the 8 letter words from the Balota et al. stimulus set, maintaining 84 sentence frames from the original 96 sentence frames. The average word length of the reduced stimulus set was 4.7 characters.

For each sentence, the target word was always the predictable word, and there were six possible previews that were either taken from the Balota et al. study or adapted given the criteria below for constructing the nonword previews. (An example is shown in Table 1.) The preview was either the predictable $(P)$ word (e.g. liver), an unpredictable $(U)$ word (e.g. heart), or a word that was semantically anomalous $(S A)$ in the sentence frame (e.g. files). The materials for these three conditions came from the original study. The visually similar condition $(V S)$ was formed by altering the penultimate letter of the predictable word, creating a non-word (e.g. livor). If the penultimate letter was an ascender or a descender, this letter was replaced by respectively an ascender or descender. The same procedure was used to make the preview for the visually dissimilar $(V D)$ condition (e.g. heant, which is visually dissimilar to the predictable word) where the base word was the unpredictable word. Finally the condition, which for the sake of convenience will be called the orthographically illegal (OI) condition, was a non-word whose first three letters always constituted a unpronounceable combination that does not appear in the English language as letters at the beginning of a word (e.g. frhos). The previews were always the same length as the target. The average word frequency, based on the Francis and Kuĉera (1982) norms were 58.2 per million for the predictable words, 58.1 per million 
for the unpredictable words, and 88.9 per million for the semantically anomalous words. As each of the 84 sentence frames was read only once by a participant, there were 14 sentences per condition per participant. The 84 experimental sentences were embedded in a pseudorandom order in 60 filler sentences.

\section{INSERT TABLE 1 ABOUT HERE}

Procedure. When a participant arrived for the experiment, a bite bar was prepared, which served to eliminate head movements. Participants were given a general description of the experimental procedure and were asked to read sentences on the monitor as their eye movements were monitored. They were also told that they would be asked questions about the sentences and were instructed to read for comprehension. The initial calibration of the eye-tracking system required about 5 minutes. Each participant read 10 practice sentences to become familiar with the procedure. Prior to the presentation of each sentence, a series of five boxes appeared on the monitor, extending from the first to the last character position of an 80character sentence. During this calibration check, participants looked at each box so that the experimenter could verify that the eye position was accurately recorded. If the calibration was not accurate, the participant was recalibrated. If the calibration was accurate, the participant looked at the first box and the experimenter displayed the sentence. Questions about the meaning of the sentence were asked after $25 \%$ of the trials and participants had little difficulty answering the questions (accuracy 96\%). The experiment lasted about 35 minutes.

\section{RESULTS}

Our primary interest in this experiment was the probability of skipping the target word during the first pass through the text (not taking regressions into account). In addition to the overall skipping probability, we examined the skipping probability conditional on the distance of the launch sites from the target word. For the cut-off point between a close and a far launch site we chose 5 character positions, since this allowed an approximately even division of the data (45\% of the saccades, regardless of whether the target word was skipped or fixated, were launched from 5 or fewer character positions from the space in front of the target word).

We also calculated the fixation times on the target word. When the target word was fixated, in $91.7 \%$ of the cases it received a single fixation. Therefore, we will restrict the fixation duration analyses to when there was a single fixation on the target word. Since our materials in this experiment were identical up to the target word, we 
were also able to examine the fixation duration of the last fixation prior to either skipping of or landing on the target word. And finally, although not the focus of the present article, we also examined the fixation duration prior to the target word regardless of whether it was skipped or not as our incorrect previews constitute an interesting situation for examining potential parafoveal-on-foveal effects. Fixation durations of less than $100 \mathrm{~ms}$ and more than $1200 \mathrm{~ms}$ on the target word were removed from the analyses. Trials on which the eye-tracker lost track of the eye position were also excluded from the analyses, as well as trials in which the eyes triggered the boundary but remained on the word before the target (usually the last letter of this word $)^{4}$. Finally, when the fixation duration was greater than three standard deviations from the mean for that participant in that condition, it was also removed (this was the case for 1 observation). As a result, about $16 \%$ of the trials were excluded from the analyses, and these trials were approximately equally distributed across conditions ${ }^{5}$. A series of repeated measures analyses of variance (ANOVAs) were undertaken with participants (F1) and items (F2) as random variables.

Skipping the target word. The skipping rates associated with Experiment 1 are shown in Table 2. The effect of preview on the skipping rates of the target word during first pass reading was close to significant, $F 1(5,115)=2.13, M S e=96, p=$ $.067, F 2(5,415)=1.962, M S e=440, p=.083$. Contrasts showed that this was mostly due to the $5 \%$ difference in skipping rate between the predictable word preview and the average of the other five conditions, $F 1(1,23)=6.18, M S \mathrm{e}=116.26, \mathrm{p}<.05$; $F 2(1,83)=5.16, M S e=589.14, \mathrm{p}<.05$. There also appeared to be a difference between the U, SA, and VS condition on the one hand and the VD and OI condition on the other; however, contrasts showed that this was not significant, $F 1(1,23)=3.76$, $M S e=68.96, \mathrm{p}>.05 ; F 2(1,83)=1.82, M S \mathrm{e}=320.16, \mathrm{p}>.10$. In addition, there was no longer any significant effect of preview when the predictable condition was removed from the analysis $\left(F_{\mathrm{S}}<1\right)$.

\section{INSERT TABLE 2 ABOUT HERE}

When we restricted the data set to saccades launched from five or fewer character positions from the target word, the effect of preview on the skipping rates

\footnotetext{
${ }^{4}$ On some occasions, the Dual Purkinje Eye-tracker will register a saccade that crosses the boundary (triggering the display change), but the eye then (within a few milliseconds) "hooks" back to land on a character prior to the boundary location.

${ }^{5}$ Deleted cells were treated as missing cases.
} 
was significant, $F 1(5,115)=3.35, M S \mathrm{e}=291.2, \mathrm{p}<.01 ; F 2(5,415)=3.14, M S \mathrm{e}=$ $1573, \mathrm{p}<.01$. A predictable word was skipped $14 \%$ more often than the average of the other conditions, $F 1(1,23)=17.54, M S e=235.79, \mathrm{p}<.001 ; F 2(1,83)=16.30$, $M S e=1568.25, \mathrm{p}<.001$, and there was no significant difference among the other five conditions $(F \mathrm{~S}<1)$. Finally, when the skip was launched from six or more character positions from the target word, there was virtually no difference among the conditions, with skipping rates being low in all conditions $\left(F_{\mathrm{S}}<1\right)$.

Table 2 also includes the overall skipping probability. In this measure, if the word was initially skipped but then regressed back to, it isn't counted as a skip. This presumably should index whether the reader realized there was something wrong after they skipped the target word. In the original Balota et al. study there was no difference in this measure between the $\mathrm{P}$ and the VS condition. The effect of preview on these skipping rates was significant, $F 1(5,115)=3.66, M S \mathrm{e}=0.01, \mathrm{p}<.01 ; F 2(5,415)=$ $3.46, M S e=0.04, p<.01$. Contrasts showed that this variance was again mainly due to the $8 \%$ difference between the predictable word and the other conditions, $F 1(1,23)$ $=11.71, M S \mathrm{e}=0.01, \mathrm{p}<.01 ; F 2(1,83)=9.42, M S \mathrm{e}=0.05, \mathrm{p}<.01$. There was no significant difference among the other five conditions, $F 1(4,92)=1.06, M S e=0.01, p$ $>.20 ; F 2(4,332)=1.32, M S \mathrm{e}=0.04, \mathrm{p}>.20$. Although the overall skipping appears to be a bit smaller for non-word previews than for word previews, this effect was not significant, $F 1(1,23)=2.24, M S e=0.01, \mathrm{p}>.10 ; F 2(1,83)=1.52, M S e=0.04, p>$ .20 .

Fixation times. Fixation times in Experiment 1 are shown in Table 3. As mentioned above, since the vast majority of gaze durations on the target consisted of a single fixation, we shall only report the single fixation duration, the mean fixation duration when there was a single fixation on the target ${ }^{6}$. The effect of preview on the single fixation duration times was significant, $F 1(5,115)=11.42, M S \mathrm{e}=638, \mathrm{p}<$ $.001 ; F 2(5,415)=5.81, M S e=4362, \mathrm{p}<.001$. Contrasts showed that three groups could be distinguished: the fixation times in the predictable condition were about 20 ms less than those in the U and VS conditions, which were in turn about $20 \mathrm{~ms}$ less than those in a $3^{\text {rd }}$ group containing the SA, the VD and the OI conditions. However, some of the comparisons were no longer significant in the analysis across stimuli after the $\mathrm{p}$ values were Bonferroni adjusted (P versus $\mathrm{U} \& \mathrm{VS}, F 1(1,23)=8.65$, MSe $=$

\footnotetext{
${ }^{6}$ Single fixation durations and gaze durations show exactly the same pattern.
} 
724.43, $\mathrm{p}<.01, F 2(1,83)=4.49, M S \mathrm{e}=3803.32, \mathrm{p}<.12 ; \mathrm{U} \&$ VS versus $\mathrm{S}, \mathrm{VD} \&$ OI, $F 1(1,23)=9.17, M S \mathrm{e}=1524.33, \mathrm{p}<.01 ; F 2(1,83)=13.69, M S \mathrm{e}=3623.54, \mathrm{p}<$ .001 ; P versus $\mathrm{S}, \mathrm{VD}, \& \mathrm{OI}, F 1(1,23)=61.62, M S \mathrm{e}=510.85, \mathrm{p}<.001, F 2(1,83)=$ $25.70, M S e=3851.90, \mathrm{p}<.001)$.

\section{INSERT TABLE 3 ABOUT HERE}

The effect of preview on fixation durations prior to the target word was not significant (all $F_{\mathrm{S}}<1$ ) (shown in Table 3, columns 2), regardless of whether the target word was skipped or fixated. An examination of the means, however, indicates that the overall fixation time in the predictable word condition was somewhat shorter than in the other conditions. To make sure we did not miss a potential parafoveal-on-foveal effect on these viewing times, we divided the fixations into two categories: those that were close to the target word and those that were further away, and computed the mean fixation times separately for these two categories. We selected a cut-off point such that the close launch sites were three character positions or fewer from the target word and the far launch sites were four or more character positions from the target word because this cut-off allowed the most even division of the data $(42.4 \%$ of the data were in the near launch site category). These fixation times are shown in Table 3 (column 3 and 4 ). The effect of preview was not significant (all $F \mathrm{~s}<1$ ) but contrasts showed that the 20-25 ms difference between the fixation duration in the predictable condition and the other conditions was significant for the analysis across participants, $F 1(1,20)=6.06, M S \mathrm{e}=1980.93, \mathrm{p}<.05$, but not for the analysis across items, $F 2<1$. There were clearly no reliable differences among the conditions when the launch site was at least three characters from the target word (all $F_{\mathrm{S}}<1$ ).

Turning to the question of whether there was an inflated fixation duration prior to skipping, when we compared the last fixation duration on the prior word conditional on whether the target word was skipped (shown in Table 3, columns 5 and 6), we did indeed find that this fixation time was about $34 \mathrm{~ms}$ greater when the target word was skipped than when it was fixated, $F 1(1,8)=15.17, M S \mathrm{e}=3129.38, \mathrm{p}<$ $.001^{7}$.

\section{DISCUSSION}

\footnotetext{
${ }^{7}$ No $F 2$ analyses are reported for this comparison due to a high number of missing cells in the fixation duration prior to skipping matrix. The high number of missing cells also made any further analysis for these data unwarranted.
} 
We had anticipated replicating the finding by Balota et al. (1985) that there was no significant overall difference in skipping rates between a predictable word and the nonword that was visually similar to it, but that we would find a difference when the prior fixation was at a suitably close launch site. Contrary to our expectations, we found that there was a difference between the predictable words and the visually similar nonwords in both the overall analysis and the analysis restricted to a close launch site, even though the visual similarity between the P and VS condition was higher than in the original study. In fact, we found little difference in skipping among the conditions in which the preview was not the predictable word. One possibility for the discrepancy between the present study and the original study may be the viewing conditions of the experiments. First, the quality of monitors has improved (with many more pixels per character) in the 20 years between the original study and the present study. This may have made extraction of parafoveal information more efficient in the present study. Second, in the original study, three characters equaled 1 degree of visual angle, whereas in the present study 3.8 characters equaled 1 degree of visual angle. This closer packing of the information in the present study may have also made extraction of parafoveal information more efficient. Thus, the original lack of finding a difference between the predictable and the visually similar conditions may have been due to poorer parafoveal viewing conditions. The present findings are therefore consistent with the assumption that the decision to skip the target word was based on a full analysis of the parafoveal word, as the difference between the $\mathrm{P}$ and the VS condition was a single letter. In contrast, the skipping rates of the VS condition were not different of those of the VD condition even though the orthographic difference was large. It should also be noted that virtually the entire skipping effect occurred when the launch site was close, again indicating that the effect was likely to be due to fairly full processing of the skipped word.

Another interesting finding in the skipping data is the lack of difference between the non-predictable conditions. In the original Balota et al. (1985) study, there were also no significant differences between the N, VD and SA conditions, but this could have been due to floor effects. The fact that there is no difference in skipping between a neutral word and a semantically anomalous word in the present study could be expected based on previous research (Altarriba, Kambe, Pollatsek, \& Rayner, 2001; see also Rayner, Balota, \& Pollatsek, 1986) showing that semantically related words are not skipped more often than semantically unrelated words. In the E- 
Z Reader model this finding is explained by stating that the decision to skip a word is instigated by the completion of the first phase of word identification of the target word. Whereas predictability appears to boost performance in this phase, the extraction of semantic features from the parafoveal word apparently does not (or at least doesn't do it fast enough), explaining the lack of an effect of semantic inhibition in the SA condition. Indeed, the mechanism explaining skipping behavior incorporated in the E-Z Reader model does not make any differential predictions on skipping behavior in terms of inhibition. Rayner and Well (1996) showed that to obtain an effect of predictability on skipping you need a large enough difference between the predictable and the unpredictable target words in terms of sentence completion ratio. A medium constraint target word resulted in faster viewing times when the target word was actually fixated but did not differ from an unpredictable word in terms of skipping. The system apparently decides to cancel the planned saccade to the target word only when the speed of the first phase of word recognition of the target word is boosted a lot.

Further evidence for a restriction of this mechanism to the condition with the predictable preview is provided by the strength of the word length effect in the current experiment. As noted previously, a considerable amount of prior research has clearly demonstrated that short words are skipped more often than long words, presumably due to reduced visibility in the case of long words. If the skipping rates are higher in the predictable condition due to enhanced word recognition of the target word, then the low-level visual effect of word length would be relatively smaller as compared to the other conditions that do not have this influence. We ran a simple regression analysis on the skipping data of the six conditions with word length as a predictor. Word length was not a significant predictor for the skipping rates in the predictable condition $(\mathrm{P}: F(1,82)=1.33, \mathrm{p}>.20)$ but was in all the other conditions $(\mathrm{U}: F(1,82)=$ $23.77, \mathrm{p}<.001$; SA: $F(1,82)=3.91, \mathrm{p}=.05$; VS: $F(1,82)=9.17, \mathrm{p}<.01$; VD: $F(1,82)$ $=7.30, \mathrm{p}<.01 ;$ OI: $F(1,82)=17.68, \mathrm{p}<.001)$. Even though we have no doubt that, given a very large data set, the effect of word length in the predictable condition would also become a significant predictor, we take this analysis as some indication that there is a less pronounced word length effect in the predictable condition because of enhanced encoding of the parafoveal target word due to its predictability from the preceding context. Taking all these arguments into account, the fact that the 5 nonpredictable conditions do not differ from each other is in agreement with the E-Z 
Reader model. However, what is incompatible with the model is the high rate of skipping "garbage" words and nonwords, an issue we will address in more detail in the General Discussion.

The single fixation durations on the target showed a pattern of $\mathrm{P}<\mathrm{U}$ and $\mathrm{VS}<$ $\mathrm{SA}, \mathrm{VD}$, and OI. That the predictable word should receive the shortest fixation times is not surprising, since it was the only condition in which the preview matched the target word after the boundary change had occurred. That some inhibition could be expected from the S, VD, and OI condition is also not surprising. The fact that the target word in the VS condition was read faster was undoubtedly due to orthographic overlap with the target word after the reader had landed upon it, however this orthographic overlap was not strong enough for the visually similar non-word to be read significantly faster $(5 \mathrm{~ms})$ than the unpredictable word, perhaps due to some inhibition from the non-wordness of the VS preview attenuating the orthographic overlap advantage.

The fixation durations prior to the target word were very interesting. We did find that the fixation duration prior to skipping a word was inflated, adding further evidence for the existence of this effect (Pollatsek et al., 1986). Furthermore, we found that when the eyes were very close to the target word (three or fewer character positions), the fixation durations in the five non-predictable conditions were longer than the fixation durations in the predictable preview condition. We will also defer discussion of these two effects to the General Discussion.

\section{EXPERIMENT 2}

The primary goal of Experiment 2 was to explore whether there is an influence of foveal load on the skipping of the following word. Previous research (Henderson \& Ferreira, 1990; Kennison \& Clifton, 1995; White et al., 2005) demonstrated that a high foveal load leads to reduced parafoveal preview benefit. In the E-Z Reader model, a word is skipped because it is recognized in parafoveal vision. Thus, it follows that the chances of recognizing the parafoveal word would be reduced when the amount of parafoveal preview is reduced. Accordingly, we expected that a high foveal load would lead to a reduced skipping rate of the following word. As we noted earlier, a prior study (White, 2004) did not find an effect of foveal difficulty of word on skipping rates of word $_{n+1}$. However, there may have been a power problem as the skipping rates in this study were quite low, probably because 5-6 letter foveal words and 4 letter target words were used. As a result, we used shorter words for both the 
foveal words whose difficulty is being manipulated (5 letters) and for the ensuing target words that are being examined for skipping probabilities (3 letters). Note that the same prediction is made by parallel models that assume a constant competition for processing resources between the different words; a difficult word will use most of the resources leaving few resources for the processing of the other words. Because less parafoveal processing has occurred, the next word will become a more attractive candidate to program a saccade to, and thus it is less likely to be skipped.

\section{METHOD}

Participants. Twenty members of the University of Massachusetts community participated in this experiment. All participants were native speakers of American English and had 20/20 vision or contact lenses. They were either given extra credit in a Psychology course or paid $\$ 8$ for their participation.

Apparatus. The apparatus was the same as in Experiment 1.

Materials. 32 sentence frames were created so that the word prior to the target word was either a low- or high-frequency adjective ${ }^{8}$. The mean frequencies, as assessed in the Francis and Kucera norms (1982), were 5 counts per million for the low-frequency adjectives and 270 counts per million for the high frequency adjectives. Word length was controlled: the word prior to the target word was always a 5 letter word adjective, and the target word was always a 3 letter noun. The mean frequency of the three letter target words was 135 counts per million. Two possible previews were created: a correct preview and a misspelled preview. In the misspelled condition, the middle letter of the 3 letter noun was always replaced by the letter $x$. This manipulation ensured that all resulting non-words were illegal non-words. As Experiment 1, in which we made the visually similar preview as visually similar to the target word as possible (by maintaining ascenders and descenders) showed a significant difference between the visually similar and identical preview conditions, we thought the manipulation here of orthographic similarity (a difference of one character) was sufficient. The combination of the two possible adjectives preceding the target (low- and high-frequency) and the two possible previews (correct and incorrect) produced a 2 x 2 design of which an example is given in Table 4. As each of the 32 sentence frames was read only once by a participant, there were 8 sentences per condition per participant. The 32 experimental sentences were embedded in a

\footnotetext{
${ }^{8}$ All materials are available from the first author upon request, denis.drieghe@ugent.be
} 
pseudorandom order in 112 filler sentences. The boundary was set, as in Experiment 1 , between the last letter of the prior word and the space preceding the target word.

To ensure that any differences that were found between the skipping of a target word preceded by either a low- or high-frequency adjective were not due to differences in predictability, we assessed how predictable the target words were in the two frequency conditions. Fourteen participants who did not participate in the eyetracking study were given the sentence frame up to and including one of the two possible preceding adjectives, and were asked to generate the next word in the sentence. In fact, there was virtually no difference in predictability between the two conditions: the target word was generated $6.25 \%$ of the time given the sentence frame with a high-frequency adjective and $6.70 \%$ of the time given the sentence frame with a low-frequency adjective.

\section{INSERT TABLE 4 ABOUT HERE}

Procedure. The procedure was the same as in Experiment 1.

\section{RESULTS}

Our primary interest in this experiment was the probability of skipping the target word during the first pass through the text. We will also report the fixation times on the word prior to the target word, to confirm that our frequency manipulation was effective, and fixation times on the target word. The latter is interesting in terms of replicating the basic finding of Henderson and Ferreira (1990) that the parafoveal preview benefit is reduced in the case of high foveal load. Contrary to Experiment 1, we will not report an analysis of the fixation duration on the word prior to the target word as a function of skipping or landing, or as a means to look for potential parafoveal-on-foveal effects. Because the word prior to the target word was not identical in every condition, both the suitability of this design and its statistical power to examine these effects is considerably reduced.

As the target word was very short, it is not surprising that in the vast majority of the cases when there was a fixation on the target word, only one fixation occurred (97.5\%). Therefore, as in Experiment 1, only single fixation durations will be reported for the target word. Since one of the manipulations was foveal load, it is of course essential that the word prior to the target word was fixated. Therefore we will restrict all our analyses to those trials in which there was a single fixation on the adjective preceding the target word. A single fixation on the adjective was the most frequent 
event when the word was fixated (94.6\%), but more importantly, single fixation duration is the cleanest measure to use in this situation, as a second fixation would allow two opportunities to get a parafoveal preview, making the analysis unnecessarily complicated.

Target fixation durations of less than $100 \mathrm{~ms}$ and more than $1200 \mathrm{~ms}$ were removed from the analyses, as well as trials on which the eye-tracker lost track of the eye position. We also removed trials in which the eyes triggered the boundary but remained on the word before the target (usually on its last letter). Finally, when the fixation duration was greater than three standard deviations from the mean for that participant in that condition, it was also removed (this was the case for 1 observation). All in all, the reported analyses were carried out on 572 trials, or $74 \%$ of all the trials ${ }^{9}$. Because a Latin square design was used with relatively few observations in the different cells, the counterbalancing group variable was included in all analyses reported below to increase the power of the design (Pollatsek \& Well, 1995). A series of 2 (foveal load) x 2 (preview) repeated measures analyses of variance (ANOVAs) were undertaken with participants (F1) and items (F2) as random variables.

Skipping the target word. The skipping probabilities in Experiment 2 are shown in Table 5 . The $12 \%$ overall difference between the correct and incorrect preview conditions was significant, $F 1(1,16)=7.16, M S \mathrm{e}=372.4, \mathrm{p}<.05 ; F 2(1,27)=$ $5.79, M S e=517.1, p<.05$, and the $8 \%$ overall difference between conditions with high and low foveal load was significant across participants, $F 1(1,16)=7.14, M S e=$ $191.9, \mathrm{p}<.05$, and marginally significant across items, $F 2(1,27)=3.46, M S e=302.2$, $\mathrm{p}=.07$. Although there was a greater effect of the correctness of the preview in the high foveal load conditions than in the low foveal load conditions, the interaction of correctness by foveal load was not close to significant, $F 1<1, F 2(1,27)=2.70, M S e=$ 585.3, $\mathrm{p}=.11$. Post-hoc t-tests revealed that there was no significant difference in skipping between a correct and an incorrect preview in the case of a low foveal load, $t 1(19)=-1.21, \mathrm{p}>.20 ; t 2<1$, nor was there between a high foveal load and a low foveal load in the case of a correct preview, all $t \mathrm{~s}<1$. These results indicate that most of the variance in the skipping data can be accounted for by the difference in skipping rate between an incorrect preview with a high foveal load, and the other three conditions.

\footnotetext{
${ }^{9}$ Deleted cells were treated as missing cases.
} 


\section{INSERT TABLE 5 ABOUT HERE}

Fixation times. The fixation times are shown in Table 6. For single fixation durations on the adjective prior to the target word there was a $27 \mathrm{~ms}$ effect of foveal load (i.e., the frequency of the adjective), $F 1(1,16)=7.01, M S \mathrm{e}=2106, \mathrm{p}<.05$; $F 2(1,27)=4.81, M S \mathrm{e}=2700, \mathrm{p}<.05$, but there was no effect of the correctness of the preview of the following noun (all $F_{\mathrm{S}}<1$ ), nor any interaction between these two factors (all $F_{\mathrm{s}}<1$ ). The $15 \mathrm{~ms}$ effect of correctness of the preview in the low foveal load condition was also not significant, $t 1(19)=-1.34, \mathrm{p}=.19 ; t 2(31)<1$.

\section{INSERT TABLE 6 ABOUT HERE}

For the single fixation duration on the target word itself both the $39 \mathrm{~ms}$ advantage when the preview was correct, $F 1(1,13)=4.78, M S \mathrm{e}=2141, \mathrm{p}<.05$; $F 2(1,21)=11.89, M S e=2399, \mathrm{p}<.01$, and the $29 \mathrm{~ms}$ advantage when the foveal load was low were significant, $F 1(1,13)=5.47, M S e=5380, \mathrm{p}<.05 ; F 2(1,21)=5.43$, $M S e=3911, p<.05$ (this latter effect could be a frequency spillover effect). The very small ( $3 \mathrm{~ms})$ interaction between these two factors in the predicted direction was not close to significant (all $\left.F_{\mathrm{S}}<1\right)$.

\section{DISCUSSION}

Even though our frequency manipulation on the word prior to the target word was effective, we did not replicate the basic finding of Henderson and Ferreira (1990; see also Kennison \& Clifton, 1995; Schroyens et al. 1999; White et al., 2005) that the parafoveal preview benefit is reduced in the case of a high foveal load; there was only a small and insignificant interaction between the foveal load and the preview condition on the single fixation duration on the target word. What we did find were large main effects of foveal load and preview condition on the single fixation times: an average $39 \mathrm{~ms}$ effect of preview and an average $29 \mathrm{~ms}$ effect of foveal load.

A possible explanation for this discrepancy could lie in the difference in how the incorrect preview was implemented in the studies. In the Henderson and Ferreira (1990) study, both a visually similar parafoveal preview and a visually dissimilar parafoveal preview were used besides the correct preview, and whereas the similar preview maintained the first three letters of the correct preview, the dissimilar preview 
consisted of a random string of letters ${ }^{10}$. The effects reported by Henderson and Ferreira were entirely due to the difference in preview benefit observed between the correct and the visually similar condition on the one hand and the dissimilar condition on the other hand. Based on this analysis, it is possible that our incorrect preview was not dissimilar enough to elicit the interaction because only the middle letter was changed in the incorrect preview condition. However, that explanation seems unlikely because we did obtain large preview effects (i.e, differences between the correct and incorrect preview) on the fixation times on the target word. In addition, a large spillover effect from the frequency manipulation on the prior word was also observed, indicating that our foveal load manipulation was powerful. So while our experiment did not replicate the interaction effect of preview and foveal load reported by Henderson and Ferreira (1990), we did obtain substantial preview and foveal load effects. Spillover has been explained within the E-Z Reader model as one of the consequences of a reduced parafoveal preview. A large foveal load will reduce the amount of parafoveal processing that can be done before the eyes arrive on the next word, causing a longer fixation after a difficult word because more processing is still left to be done in order to identify the newly fixated word. So while our fixation times on the target did not replicate a reduced parafoveal preview, as it is traditionally assessed by comparing the fixation time when there was a correct preview versus an incorrect preview, there were indications that our foveal load manipulation was effective in reducing the amount of parafoveal processing. We will explore alternative explanations for the essentially additive pattern of data we obtained in the General Discussion.

Turning to the skipping rates, effects of foveal load and preview were also observed, but mostly because the skipping rate of the incorrect preview with a high foveal load was considerably lower than the other conditions. We should note that our pattern of skipping rates is similar to that of White (2004) except that she did not obtain any significant effect of foveal load on skipping rates. That is, she also found that the lowest skipping rates were associated with a high foveal load and an incorrect preview. Although the patterns of effects observed in the single fixation times and the skipping rates seem to suggest a common underlying cause (i.e. reduced parafoveal

\footnotetext{
${ }^{10}$ A random string of letters also constituted the incorrect preview in the Kennison and Clifton and White et al. studies, whereas Schroyens, et al. (1999) used a random permutation of pixels. No visually similar condition was used in these studies.
} 
processing), the fact that the high foveal load and incorrect preview condition stands out in the skipping data leads us to believe that the story may be more complicated for saccade target selection. We will also discuss this issue further in the General Discussion.

\section{GENERAL DISCUSSION}

We will first discuss what we think we have learned about the causes of skipping, then discuss the effects of skipping on processing neighboring words, and finally touch on related issues, such as the effects of our manipulations on the fixation durations on the target word and neighboring words.

The first issue is why words are skipped. Our data raise two issues: (a) the causes for the differences in skipping rate between our conditions and (b) why letter strings are skipped even when they are nonwords or words that are anomalous in the sentence context. Clearly, the fact that we obtained differences in skipping rate for target words as a function of the letters that were there (with the length of the letter string held constant) indicates that processing of the word to the right of fixation is influencing the frequency with which it is skipped. Moreover, this assertion is relatively uncontroversial. However, the extent of the processing of the skipped word that is causing these differences in skipping rates remains an issue of some debate in the literature (e.g. Radach \& Kennedy, 2004; Rayner \& Juhasz, 2004; Reichle, Rayner, \& Pollatsek, 2003). For example, the E-Z Reader model (Reichle et al., 1998, 2003) posits that one of the primary mechanisms for skipping a word is when a word $\left(\right.$ word $\left._{n+1}\right)$ is recognized very quickly in parafoveal vision. This very rapid recognition produces a program to fixate the following word $\left(\operatorname{word}_{n+2}\right)$, which occurs early enough to cancel the program to fixate $\operatorname{word}_{n+1}$. In contrast, other models (e.g. Brysbaert et al. 2005; Brysbaert \& Vitu, 1998; Drieghe et al., 2004) assume that skipping is based on coarser visual information.

A major motivation for Experiment 1 was that Balota et al. (1985) found no difference between the skipping rates for a predictable word and for a non-word that was visually similar to the predictable word - a finding at odds with the assumption that full processing of the parafoveal word was a major cause of skipping. As we argued earlier, however, such a pattern might occur when the launch site for a typical saccade comes from some distance from the skipped word, and thus the difference between the predictable word and a nonword that is orthographically similar to it might not be discriminated by the visual system. As a result, we attempted to 
replicate the experiment, but examining carefully the locations of where saccades were launched that either did or didn't result in skipping the target word. Our findings were (a) that there was a large difference in skipping probability between the predictable word and the visually similar nonword from near launch sites, but (b) almost no difference in skipping probability between these conditions from far launch sites.

This, of course, raises the question of why there was a difference between the two experiments. One possibility is that virtually all of the skipping in the Balota et al. study was from far launch sites; however, this seems improbable. Instead, we think that the most likely reason for the difference between the two experiments is that the parafoveal information was more difficult to extract in the original Balota et al. experiment, largely because the font in their display system was not nearly as legible as the fonts in current computer display systems and possibly because our words, on average were somewhat shorter than in Balota et al. As a result, we think the discrepancy between the present results and those obtained by Balota et al. indicates that one needs comparable viewing conditions across studies in reading in order to be sure that one can be sure about why there are differences in the patterns of data in two studies.

If one only pays attention to significant results, this would be the end of the story: predictable words are skipped more than anything else in the same location. However, there is a suggestion that the words in the other two parafoveal word conditions and the nonwords in the visually similar condition were skipped a bit more (3-4\%) than the other two nonword conditions. In terms of the E-Z reader model, this could be explained by assuming (a) that the words in the other two conditions were identified rapidly a small fraction of the time without the aid of predictability and (b) that the visually similar nonword was occasionally misidentified as the predictable word. However, it is an open question as to whether this could really be predicted by the model quantitatively.

In sum, the results of Experiment 1 indicate that the differences in skipping rates between the conditions is based chiefly on a complete identification of the word in the parafovea, consistent with the E-Z Reader model. Moreover, we think we have made a strong test of this because the difference between the predictable word and the visually similar non-word was a single letter. This leaves open the question of why there was over a $10 \%$ skipping rate even for nonwords that presumably didn't look 
like any word. The two mechanisms posited by E-Z Reader seem the most plausible. First, there is quite a bit of evidence that indicates that there is error in saccadic programming, such that there is a non-trivial probability that the word targeted is not the word fixated. Thus, there is a reasonable probability that a saccade intended for the target word or nonword overshot the word and resulted in a skip. There is some confirmation for this hypothesis when one looks at the regressions back to the target word. When the preview was the predictable word, the rate was only $2 \%$, whereas it varied from $3-7 \%$ in the other conditions, suggesting that the preview was processed, intended to be fixated, and then there was a "double-take". A second mechanism posited by E-Z Reader 8 (Pollatsek et al., 2005; Rayner et al., 2005) is that some skipping is based solely on predictability. That is, a decision is made to skip the following word based on no visual information other than that the parafoveal string is approximately the length of the predicted word. Whether these two mechanisms can predict a $12 \%$ skipping rate for orthographically illegal strings of the correct length is an open question.

Are the results of Experiment 2 compatible with these conclusions? As indicated earlier, the major results of Experiment 2 were: (a) that a correct preview of the target word was skipped more than a visually similar nonword; (b) that skipping rates were higher when the word before the target word was higher frequency; (c) but that most of the above two differences were due to skipping rates being lower for nonword previews preceded by low frequency words than in the other three conditions. The first finding of a difference in skipping rates between the correct word and the nonword is quite compatible with Experiment 1. As the target words were short and relatively frequent, identification times for these words could have been short enough to produce increased skipping, even without being predictable. Similarly, making the prior word lower frequency would delay the beginning of parafoveal processing (according to the E-Z Reader model) and thus reduce the amount of skipping.

There are two problematic aspects to the data, however: the pattern of the effects mentioned in point (c) above; and the fact that skipping rates were still $25 \%$ in the worst condition (a nonword following a low-frequency word). Let's consider the second phenomenon first. Are these skipping rates abnormally high? First, the target words are all short reasonably high frequency nouns. As a result, one would expect them to be identified reasonably quickly, especially as the prior words were also 
reasonably short (about 5 letters) and thus the fixation prior to the target word was likely to be pretty close to it. However, this doesn't explain why visually similar nonwords would also be skipped. The simplest explanation is that some of the time, the nonword is misidentified as the word and that, in these cases, the misidentification doesn't slow processing all that much. This explanation, however, appears to run into trouble because when fixation times on the target word were examined there was a healthy (35-40 ms) difference in fixation time between when the correct and incorrect preview were presented. This might not be a problem, though, if one considers the cases when the target word was skipped as those trials when the incorrect (middle) letter was misidentified and the cases when the word was fixated as those trials when the incorrect letter was correctly identified. Clearly, this is a speculative post-hoc explanation that would need to be verified somehow. To interpret the size of the skipping rates obtained in Experiment 2, it is also important to note that the analysis was restricted to instances in which the reader fixated on the 5-letter adjective preceding the target word (a 3-letter noun). Taking into account the fact that the average saccade length reported in the literature is 8 character positions and that the perceptual span for letter identification expands 7 to 8 letters to the right of the fixation (see Rayner, 1998 for a review of studies examining these factors), it is safe to say to our target word was in an area of high visibility and that skipping the word would not entail executing an especially large saccade ${ }^{11}$. Keeping this in mind, the selection of the fixation data carried out in Experiment 2 has another important consequence. Prior research (McConkie et al., 1988) has established the existence of a so-called range effect; the oculomotor system tends to undershoot targets at a large eccentricity and to overshoot targets at a small eccentricity. By restricting our analyses to those instances on which there was a fixation on the 5 letter adjective preceding the target word, we are also increasing the chances of involuntary overshooting of the target (as compared to studies that do not select close-by launch sites). This latter phenomenon would also explain some of the high skipping rates regardless of condition.

The pattern of the effects, however, seems harder to understand. According to the E-Z Reader model, skipping occurs only when identification of $\operatorname{word}_{n+1}$ is really rapid, and thus we had expected the opposite interaction: skipping rates would be

\footnotetext{
${ }^{11}$ In Experiment 2 the average saccade length based on the three saccades prior to encountering the target word was 7.5 character positions.
} 
higher when the preview was correct and the prior word was high frequency than those in the other three conditions. It seems more difficult to explain why there should be a bigger difference in skipping rates between the correct and incorrect preview conditions when the prior word is low frequency, and thus presumably less processing of the parafoveal word is taking place. It might seem that a possible explanation is that fixation times on the prior word are $30 \mathrm{~ms}$ longer when that word is lower frequency and thus allows more processing of the target word. However, according to the E-Z Reader model, the lower the frequency of a word, the less time there is to process the next one parafoveally because the signal for an eye movement precedes the attention shift to the next word, and furthermore the gap between these two events increases with decreasing frequency of the word. Although it is possible that a more parallel encoding model might be able to explain this interaction by pointing to the increased fixation time on the target word, it is far from clear that it can. That is, the issue is not how much total time there is to process the parafoveal word, but how much time there is before the signal to skip the word.

We also wondered whether these strange effects could be due to fast readers and slow readers each having a different pattern than the overall pattern, with the overall pattern being the result of averaging the two different patterns. Another possibility we considered was that the interaction was largely due to fast readers having developed a strategy that allows them to skip words more frequently. That is, given that fast readers make fewer fixations and have longer saccades (Rayner, 1998) they may adopt a strategy of skipping short words by default and only canceling such saccades when everything points in the direction of a long saccade being inappropriate. To examine this issue in more detail, we split our participants into two groups containing the 10 fastest readers and the 10 slowest readers, based on the overall reading speed; the 10 fastest readers had an average total viewing time of the sentences in the experiment that was shorter than $3005 \mathrm{~ms}$. As can be seen in Table 7, there was little evidence for a difference between the groups in terms of the pattern of the effects, even though the 10 fastest readers skipped $37 \%$ more, on average, and made $17 \%$ more regressions back to the target word after skipping. Thus, we view the pattern of effects in the skipping data a problem we still haven't solved.

\section{INSERT TABLE 7 ABOUT HERE}

To quickly summarize the above, in spite of a couple of aspects that are not easy to explain, the overall pattern of skipping data is consistent with the following 
principles. First, a reasonable amount of skipping is explained by the parafoveal word being easy to identify fully, either on the basis of it being predictable, short, and/or high frequency. Second, there is a residue of skipping that seems to be explained by mistargeting of saccades, which would lead to more skipping for shorter words. Third, it appears that some additional skipping might be explained when a string that is similar to either a frequent and/or predictable word is misidentified as that word. Fourth, some additional skipping might be due merely to guessing that the next stimulus is a predictable word if the parafoveal string is approximately the right length ${ }^{12}$.

Now let us move on to other phenomena related to skipping. The first is how skipping word $_{n+1}$ affects fixation times on the prior word. As indicated in the introduction, the phenomenon of inflated fixations prior to word skipping has been considered a cornerstone in the discussion of the time course of foveal and parafoveal processing. The E-Z Reader model, which posits serial processing of words, predicts a cost associated with the canceling of the saccade to $\operatorname{word}_{n+1}$ and the replacement by a saccade to $\operatorname{word}_{\mathrm{n}+2}$. Parallel models, such as SWIFT (Engbert et al., 2002) or Glenmore (Reilly \& Radach, 2003), do not assume such a cost associated with the skipping of a word. In Experiment 1, we observed a large (34 ms) inflation of fixation time on the prior word if the target word was skipped as did Pollatsek et al. (1986) and Rayner et al. (2004). Admittedly there are results to the contrary (e.g., Kliegl \& Engbert, 2004). However, as we indicated earlier, the comparison is complicated as any such comparison is correlational because the reader, and not the experimenter, decides when a word is skipped. One such correlational artifact that could work to produce these inflated times prior to skipping is that when a fixation is longer, it gives the reader more time to process the next word and hence skip it. However, we think that the most plausible artifacts of the correlational structure of this comparison would work against finding this cost due to skipping and could explain why null results are sometimes found. That is, words are more likely to be skipped by good or motivated readers (or readers paying close attention at that moment) and such readers are also more likely to produce shorter fixation times. We should point out that the existence of inflated fixation durations prior to skipping is not necessarily threatening to parallel models for the reason indicated above: longer fixation durations on the foveal word

\footnotetext{
${ }^{12}$ Although prior research (Drieghe et al., 2004) has shown that this effect is difficult to obtain in the complete absence of any orthographic overlap with the predictable target word.
} 
(e.g. due to random variations in fixation times) will allow increased parafoveal preview, and as a consequence more skipping.

The second finding is that the prior fixation durations in the five nonpredictable conditions were longer than the prior fixation duration in the predictable preview condition in Experiment 1. These results are compatible with parafoveal-onfoveal effects. However, the effect was localized to trials when the prior fixation was on the last three characters prior to the beginning of the target word. Such an effect was first reported by Rayner (1975). He found that the fixation durations at the launch site were longer when the following letter string was a nonword than when the launch site was three or fewer character positions away from the beginning of the target word (similar to our finding in Experiment 1). Rayner, Warren et al. (2004) also reported what could be assumed to be a parafoveal-on-foveal effect in a study dealing with plausibility. When word $_{n+1}$ was anomalous, Rayner, Warren et al. (2004) found that readers' fixations were longer in the three character region preceding the target word. They attributed the finding to (a few) mislocalized saccades (undershoots). It is interesting in the present experiment (as well as Rayner, 1975) that not only were the fixations longer in the three character region preceding the target word for all the other conditions than when the predictable word was in the parafovea, but the fixations on the target word region were also longer for these other conditions. This is not surprising, because when readers undershoot a target word, the duration of the mislocated fixation should plausibly be increased (because the reader is really processing the target word) and they would then fixate directly on the target word (to confirm what they have already read). But, of course, in our experiment (as well as Rayner, 1975), a display change occurs between the two fixations and the difference between the pre-display change word and the post-display change is also likely to lead to longer fixations.

To summarize this last discussion, our experiments were not really designed to examine fixation durations, and hence not designed to test these predictions of serial and parallel models of attention in reading. However, we think there is nothing in the data to indicate that the serial processing assumption of the E-Z Reader model is wrong, and the large cost of skipping on the fixation time of the prior word observed in Experiment 1 is quite compatible with such an assumption and might be hard to parallel models to predict quantitatively. 
The other issue our experiments addressed is the relationship between the difficulty of processing a word and the amount of parafoveal processing that occurs on the next word. In our discussion above, we examined this issue with respect to skipping rates, and found that the pattern of results in Experiment 2 was different from that predicted by the E-Z Reader model and also at odds with the findings reported by Henderson and Ferreira (1990; see also Kennison \& Clifton, 1995; Schroyens et al., 1999; White et al., 2005). That is, in the prior findings, there was a greater benefit from a correct preview (and/or cost from an incorrect preview) when processing the prior word was easy (e.g., high frequency). As indicated earlier, in the skipping data, we observed the opposite interaction, but in the fixation times on the target word (which was the focus of the earlier studies), we observed additive effects of whether the preview was correct or not and whether the prior word was high or low frequency. There are two differences between our stimuli and those in the prior experiments that may explain the difference. First, as indicated earlier, our incorrect preview was less distorted than the previews previously used in research examining the effects of foveal load on parafoveal processing (Henderson and Ferreira, 1990; Kennison \& Clifton, 1995; Schroyens et al., 1999; White et al., 2005), as there was only the change of a single internal letter. However, the difference in pattern between Experiment 2 and these other studies can't merely be due to insensitivity of the present design, as there was almost a $40 \mathrm{~ms}$ main effect due to the correctness of the preview in the fixation time data. Second, our target words were only three letters, and there may be something different about how these short words are processed that explains the pattern of effects, although the data do not offer any obvious clues for what would account for the difference in pattern.

The prediction of the E-Z Reader for the interactive pattern in which there is a bigger preview effect when the prior word is high frequency is based on the assumption that the second stage of lexical processing, $\mathrm{L}_{2}$ is solely a function of word frequency. However, this is undoubtedly an oversimplification and other factors are likely to come into play. One possibility is that competition among possible lexical entries is another factor influencing the later aspects of word identification. In an activation-verification model (Paap, Newsome, McDonald, \& Schvaneveldt, 1982), for example, such a competition among lexical entries is explicitly the second stage of lexical access. Thus, one possibility for three letter words is that the frequency of the word is only a minor determinant of the time for later stages of word identification, 
and that factors such as neighborhood size and whether there is a higher frequency neighbor play a more important role in these later stages of lexical identification and thus in the amount of preview benefit. This process might also be modulated by a rapid identification of the "outside" letters relative to identification of the middle letter due to less lateral inhibition of these letters.

In conclusion, we have found strong evidence that word skipping is usually based on a full identification of the word in the parafovea, consistent with the mechanisms described in the E-Z Reader model. Our first experiment showed that even when a preview of a word is different from the preview of a predictable word by only one single letter, this manipulation is already sufficient to cause a difference in skipping behavior. The fact that in the second experiment our frequency manipulation on the prior word led to comparable patterns in the fixation times and skipping data of the following word adds further evidence to the argument that both factors are influenced by a common phenomenon, the amount of parafoveal processing. However, we did not find a reduced parafoveal preview benefit in the case of high foveal load as reported by Henderson and Ferreira (1990), possibly due to parafoveal processing reaching ceiling values or due to there being something different about how three-letter words are accessed. Inconsistent with earlier E-Z Reader models and with most other models of eye movements in reading (e.g. the SWIFT model, Engbert, et al., 2002), we found a non-trivial amount of skipping of "garbage" words $^{13}$. This was especially true when the eyes were close to the target word and the target word was very short. It was by the use of shorter stimuli in both experiments, as compared to most previous research on word skipping, that this finding was established. These data indicate that sometimes a reader prefers to skip a word based on more coarse information, presumably by relying on extra processing that will be done on the fixation after the target. Whether this "guessing" mechanism constitutes a real default or whether our reported results were due to individual strategies (e.g., those of fast readers) will have to be examined in future research. In both cases, models of eye movements in reading will have to take into account an amount of skipping based on an incomplete identification.

\footnotetext{
${ }^{13}$ E-Z Reader 8 (see Pollatsek et al., 2005; Rayner et al., 2005, incorporates a "guessing" mechanism from predictability that is consistent with such a phenomenon)
} 


\section{Author Note}

This research was supported by Grant HD26765 from the National Institute of Health. It was carried out when the first author was a visitor at the Eye Movement $\mathrm{Lab}$ at the University of Massachusetts, Amherst. Denis Drieghe is a research assistant of the Fund for Scientific Research (Flanders, Belgium). His stay was funded by an extra scholarship provided by the Fund for Scientific Research (Flanders, Belgium). We would like to thank Jean Saint-Aubin, Alan Kennedy, and an anonymous reviewer for their helpful critiques on a previous draft of the manuscript. 


\section{References}

Altarriba, J., Kambe, G., Pollatsek, A., \& Rayner, K. (2001). Semantic codes are not used in integrating information across eye fixations in reading: Evidence from fluent Spanish-English bilinguals. Perception \& Psychophysics, 63, 875-890.

Altarriba, J., Kroll, J. F., Sholl, A.. \& Rayner, K. (1996). The influence of lexical and conceptual constraints on reading mixed-language sentences: Evidence from eye fixations and naming times. Memory \& Cognition, 24, 477-492.

Balota, D. A., Pollatsek, A., \& Rayner, K. (1985). The interaction of contextual constraints and parafoveal visual information in reading. Cognitive Psychology, 17, 364-390.

Binder, K. S., Pollatsek, A., \& Rayner, K. (1999). Extraction of information to the left of the fixated word in reading. Journal of Experimental Psychology: Human Perception and Performance, 25, $1162-1172$.

Blanchard, H. E., Pollatsek, A., \& Rayner, K. (1989). The acquisition of parafoveal word information in reading. Perception \& Psychophysics, 46, 85-94.

Brysbaert, M., Drieghe, D., \& Vitu, F. (2005). Word skipping: Implications for theories of eye movement control in reading. In G. Underwood (Ed.), Cognitive Processes in Eye Guidance, Oxford: Oxford University Press, in press.

Brysbaert, M., \& Vitu, F. (1998). Word skipping: implications for theories of eye movement control in reading. In G. Underwood (Ed.), Eye Guidance in Reading and Scene Perception. Oxford: Elsevier, pp. 125-147.

Deutsch, A., \& Rayner, K. (1999). Initial fixation location effects in reading Hebrew words. Language and Cognitive Processes, 14, 393-421.

Drieghe, D., Brysbaert, M., Desmet, T., \& Debaecke, C. (2004). Word skipping in reading: On the interplay of linguistic and visual factors. European Journal of Cognitive Psychology, 16, 79-103. 
Ehrlich, S. F., \& Rayner, K. (1981). Contextual effects on word perception and eye movements during reading. Journal of Verbal Learning and Verbal Behaviour, $\underline{20}, 641-655$.

Engbert, R., Longtin, A., \& Kliegl, R. (2002). A dynamical model of saccade generation in reading based on spatially distributed lexical processing. Vision Research, 42, 621-636.

Francis, W., \& Kucera, H. (1982). Frequency Analysis of English Usage: Lexicon and Grammar. Boston: Houghton Mifflin.

Henderson, J. M., \& Ferreira, F. (1990). Effects of foveal processing difficulty on the perceptual span in reading: implications for theories of reading eye movements. Journal of Experimental Psychology: Learning, Memory, and Cognition, 16, 417-429.

Henderson, J. M., \& Ferreira, F. (1993). Eye movement control during reading: Fixation measures reflect foveal but not parafoveal processing difficulty. Canadian Journal of Experimental Psychology, 47, 201-221.

Inhoff, A. W., Radach, R., Starr, M., \& Greenberg, S. (2000). Allocation of visuospatial attention and saccade computation during eye fixations in reading. In A. Kennedy, R. Radach, D. Heller, \& J. Pynte (Eds.), Reading as a perceptual process. (pp 221-246). Oxford, UK: Elsevier.

Inhoff, A. W., Starr, M., \& Shindler, K. L. (2000). Is the processing of words during eye fixations in reading strictly serial? Perception \& Psychophysics, 62, 14741484.

Inhoff, A. W., \& Rayner, K. (1986). Parafoveal word processing during eye fixations in reading: effects of word frequency. Perception \& Psychophysics, 40, $431-$ 439.

Juhasz, B. J., \& Rayner, K. (2003). Investigating the effects of a set of intercorrelated variables on eye fixation durations in reading. Journal of Experimental Psychology: Learning, Memory, and Cognition, 29, 1312 - 1318. 
Juhasz, B.J., \& Rayner, K. (2004). The role of age-of-acquisition and word frequency in reading: Evidence from eye fixation durations. Visual Cognition, in press.

Kennedy, A. (1998). The influence of parafoveal words on foveal inspection time: Evidence for a processing trade-off. In G. Underwood (Ed.), Eye Guidance in

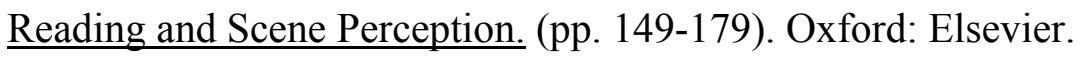

Kennedy, A. (2000). Parafoveal processing in word recognition. Quarterly Journal of Experimental Psychology, 53A, 429-455.

Kennedy, A., \& Pynte, J. (2005). Parafoveal-on-foveal effects in normal reading. Vision Research, 45, 153-168.

Kennedy, A., Pynte, J., \& Ducrot, S. (2002). Parafoveal-on-foveal interactions in word recognition. Quarterly Journal of Experimental Psychology, 55A, 13071337.

Kennison, S. M., \& Clifton, C. C. (1995). Determinants of parafoveal preview benefit in high and low working memory capacity readers: Implications for eye movement control. Journal of Experimental Psychology: Learning, Memory, and Cognition, 21, 68-81.

Kliegl, R., \& Engbert, R. (2004). Fixation durations before word skipping in reading. Psychonomic Bulletin \& Review, in press.

McConkie, G. W., Kerr, P. W., Reddix, M. D., \& Zola, D. (1988). Eye movement control during reading: I. The location of initial eye fixations on words. Vision Research, 28, 1107-1118.

Morris, R. K., Rayner, K., \& Pollatsek, A. (1990). Eye movement guidance in reading: the role of parafoveal letter and space information. Journal of Experimental Psychology: Human Perception and Performance, 16, 268-281.

O'Regan, J. K. (1980). The control of saccade size and fixation duration in reading: the limits of linguistic control. Perception \& Psychophysics, 28, $112-117$.

Paap, K. R., Newsome, S. L., McDonald, J. E., \& Schvaneveldt, R. W. (1982). An activation verification model for letter and word recognition - The word 
superiority effect. Psychological Review, 89, 573 - 594.

Pollatsek, A., \& Rayner, K. (1982). Eye movement control in reading: The role of word boundaries. Journal of Experimental Psychology: Human Perception and Performance, $8,817-833$.

Pollatsek, A., Rayner, K., \& Balota, D. A. (1986). Inferences about eye movement control from the perceptual span in reading. Perception \& Psychophysics, 40, 123-130.

Pollatsek, A., Reichle, E. D., \& Rayner, K. (2003). Modeling eye movements in reading: Extensions of the E-Z Reader model. In J. Hyönä, R., Radach, \& H. Deubel (Eds.), The Mind's Eye: Cognitive and Applied aspects of Eye Movement Research. (pp 361 - 390). Oxford, UK: Elsevier.

Pollatsek, A., Reichle, E. D., \& Rayner, K. (2005). Tests of the E-Z Reader model: Exploring the interface between cognition and eye-movement control. Submitted.

Pollatsek, A., \& Well, A. D. (1995). On the use of counterbalanced designs in cognitive research: a suggestion for a better and more powerful analysis. Journal of Experimental Psychology: Learning, Memory and Cognition, 21, 785-794.

Pynte, J., Kennedy, A., \& Ducrot, S. (2004). The influence of parafoveal typographical errors on eye movements in reading. European Journal of Cognitive Psychology, 16, 178 - 202.

Radach, R., \& Heller, D. (2000). Relations between spatial and temporal aspects of eye movement control. In A. Kennedy, R. Radach, D. Heller, \& J. Pynte (Eds.), Reading as a perceptual process. (pp 165-191). Oxford, UK: Elsevier.

Radach, R., \& Kempe, V. (1993). An individual analysis of initial fixation positions in reading. In G. d'Ydewalle \& J. Van Rensbergen (Eds.), Perception and cognition: Advances in eye movement research (pp. 213-226). Amsterdam: North Holland. 
Radach, R., \& Kennedy, A. (2004). Theoretical perspectives on eye movements in reading: Past controversies, current issues, and an agenda for future research. European Journal of Cognitive Psychology, 16, 3- 26.

Rayner, K. (1975). The perceptual span and peripheral cues in reading. Cognitive Psychology, 7, $65-81$.

Rayner, K. (1979). Eye guidance in reading: Fixation locations within words. Perception, $8,21-30$.

Rayner, K. (1998). Eye movements in reading and information processing: 20 years of research. Psychological Bulletin, 124, $372-422$.

Rayner, K., Ashby, J., Pollatsek, A., \& Reichle, E. D. (2004). The effects of frequency and predictability on eye fixations in reading: Implications for the E-Z Reader model. Journal of Experimental Psychology: Human Perception and Performance, $30,720-732$.

Rayner, K., Balota, D. A., \& Pollatsek, A. (1986). Against parafoveal semantic preprocessing during eye fixations in reading. Canadian Journal of Psychology, 40, 473-483.

Rayner, K., Binder, K. S., Ashby, J., \& Pollatsek, A. (2001). Eye movement control in reading: word predictability has little influence on initial landing positions in words. Vision Research, 41(7), 943-954.

Rayner, K., \& Duffy, S. A. (1986). Lexical complexity and fixation times in reading: effects of word frequency, verb complexity, and lexical ambiguity. Memory \& Cognition, 14, $191-201$.

Rayner, K., \& Fischer, M. H. (1996). Mindless reading revisited: eye movements during reading and scanning are different. Perception \& Psychophysics, 58(5), 734-747.

Rayner, K., Fischer, M. H., \& Pollatsek, A. (1998). Unspaced text interferes with both word identification and eye movement control. Vision Research, 38, 1129 1144. 
Rayner, K., \& Juhasz, B. J. (2004). Eye movements in reading: Old questions and new directions. European Journal of Cognitive Psychology, 16, 340 - 352.

Rayner, K., \& McConkie, G. W. (1976). What guides a reader's eye movements? Vision Research, 16, 829-837.

Rayner, K., \& Reichle, E. D., \& Pollatsek, A. (1998). Eye movement control in reading: An overview and model. In G. Underwood (Ed.), Eye Guidance in Reading and Scene Perception. Oxford: Elsevier, pp. 243-268.

Rayner, K., \& Reichle, E. D., \& Pollatsek, A. (2000). Eye movement control in reading: Updating the E-Z Reader model to account for initial fixation locations and refixations. In A. Kennedy, R. Radach, D. Heller, \& J. Pynte (Eds.), Reading as a perceptual process. (pp 701 - 719). Oxford, UK: Elsevier.

Rayner, K., Reichle, E. \& Pollatsek, A. (2005). Eye movement control in reading and the E-Z Reader model. In G. Underwood (Ed.). Eye Guidance and Cognitive Processes. Oxford: Oxford University Press, in press.

Rayner, K., Sereno, S. C., \& Raney, G. E. (1996). Eye movement control in reading: a comparison of two types of models. Journal of Experimental Psychology: Human Perception and Performance, 22, 1188-1200.

Rayner, K., Warren, T., Juhasz, B.J., \& Liversedge, S.P. (2004). The effect of plausibility on eye movements during reading. Journal of Experimental Psychology: Learning, Memory, and Cognition, 30, 1290 - 1301.

Rayner, K., \& Well, A. D. (1996). Effects of contextual constraint on eye movements during reading: a further examination. Psychonomic Bulletin \& Review, 3, 504-509.

Rayner, K., Well, A. D., Pollatsek, A., \& Bertera, J. H. (1982). The availability of useful information to the right of fixation in reading. Perception \& Psychophysics, 31, 537-550.

Rayner, K., White, S. J., Kambe, G., Miller, B., \& Liversedge, S. P. (2003). On the processing of meaning from parafoveal vision during eye fixations in reading. 
In Hyönä, J., Radach, R., \& Deubel, H. (Ed.), Cognitive and Applied Aspects of Eye Movement Research. Amsterdam: Elsevier, pp. 213-234.

Reichle, E. D., Pollatsek, A., Fisher, D. L., \& Rayner, K. (1998). Toward a model of eye movement control in reading. Psychological Review, 105, 125-157.

Reichle, E. D., Rayner, K., \& Pollatsek, A. (1999). Eye movement control in reading: accounting for initial fixation locations and refixations within the E-Z Reader model. Vision Research, 39, 4403-4411.

Reichle, E. D., Rayner, K., \& Pollatsek, A. (2003). The E-Z Reader model of eye movement control in reading: comparisons to other models. Behavioral and Brain Sciences, 26, $445-526$.

Reilly, R. G., \& Radach, R. (2003). Foundations of an interactive model of eye movement control in reading. In Hyönä, J., Radach, R., \& Deubel, H. (Ed.), Cognitive and Applied Aspects of Eye Movement Research. Amsterdam: Elsevier, pp. 429-455.

Schilling, H. E. H., Rayner, K., \& Chumbley, J. I. (1998). Comparing naming, lexical decision, and eye fixation times: word frequency effects and individual differences. Memory \& Cognition, 26, 1270 - 1281.

Schroyens, W., Vitu, F., Brysbaert, M, \& d'Ydewalle, G. (1999). Eye movements during reading: Foveal load and parafoveal processing. Quarterly Journal of Experimental Psychology, 52A, 1021-1046.

Schustack, M. W., Ehrlich, S. F., \& Rayner, K. (1987). Local and global sources of contextual constraint in reading. Journal of Memory and Language, 26, 322340.

Starr, M., \& Inhoff, A. W. (2004) Allocation of attention during eye fixations in reading. Use of orthographic information from multiple word locations. European Journal of Cognitive Psychology, 16, 203-225.

Underwood, G., Binns, A., \& Walker, S. (2000). Attentional demands on the processing of neighbouring words. . In A. Kennedy, R. Radach, D. Heller, \& J. 
Pynte (Eds.), Reading as a perceptual process. (pp 247-268). Oxford, UK: Elsevier.

Vitu, F. (1991). The influence of parafoveal preprocessing and linguistic context on the optimal landing position effect. Perception \& Psychophysics, 50, 58 - 75.

Vitu, F., Brysbaert, M., \& Lancelin, D. (2004). A test of parafoveal-on-foveal effects with pairs of orthographically related words. European Journal of Cognitive Psychology, 16, 154-177.

Vitu, F., O'Regan, J. K., Inhoff, A. W., \& Topolski, R. (1995). Mindless reading: eyemovement characteristics are similar in scanning letter strings and reading texts. Perception \& Psychophysics, 57, 352-364.

Vonk, W. Radach, R., \& van Rijn, H. (2000). Eye guidance and the saliency of word beginnings in reading text. . In A. Kennedy, R. Radach, D. Heller, \& J. Pynte (Eds.), Reading as a perceptual process. (pp 269-299). Oxford, UK: Elsevier.

White, S. J. (2004, May). Foveal processing load does not modulate the probability of skipping the following word: Implications for models of eye movement control in reading. Paper presented at the Sixth European Workshop on Language Comprehension, St Pierre d'Oléron, France.

White, S. J., Rayner, K., \& Liversedge, S. P. (2005). Eye movements and the modulation of parafoveal processing by foveal word difficulty: A reexamination. Psychonomic Bulletin \& Review, in press.

Zola, D. (1984). Redundancy and word perception during reading. Perception \& Psychophysics, 36, 277 - 284. 
Table 1. An example sentence from Experiment 1 with each of the 6 parafoveal preview conditions.

1. Predictable word.

The doctor told Fred that his drinking would damage his liver very quickly.

2. Unpredictable word.

The doctor told Fred that his drinking would damage his heart very quickly.

3. Semantically anomalous word.

The doctor told Fred that his drinking would damage his files very quickly.

4. Visually similar non-word.

The doctor told Fred that his drinking would damage his livor very quickly.

5. Visually dissimilar non-word.

The doctor told Fred that his drinking would damage his heant very quickly.

6. Orthographic illegal word.

The doctor told Fred that his drinking would damage his frhos very quickly.

\footnotetext{
Note: The stimuli shown in italics indicate the preview for each condition prior to the eyes' crossing of the display change boundary. The preview was always replaced by the predictable word after the boundary had been crossed.
} 
Table 2. Probability of skipping the target word during first pass for all the data (All), , saccades launched from 5 or less character positions (45\% of the data), saccades launched from 6 or more characters (55\% of the data) and for all the data not restricted to first pass (All + regr).

\begin{tabular}{|l|c|c|c|c|}
\hline \multicolumn{1}{|c|}{ Preview Conditions } & \multicolumn{3}{|c|}{ Skip critical word } \\
\cline { 2 - 5 } & All & $\leq 5$ & $\geq 6$ & All + regr. \\
\hline Predictable word & .20 & .50 & .06 & .18 \\
\hline Unpredictable word & .16 & .39 & .05 & .09 \\
\hline Sem. Anomalous word & .16 & .35 & .06 & .13 \\
\hline Visually similar non-word & .16 & .36 & .07 & .10 \\
\hline Visually dissimilar non-word & .13 & .31 & .04 & .08 \\
\hline Orth. Illegal non-word & .12 & .37 & .04 & \\
\hline
\end{tabular}


Table 3: Fixation times (in ms) of the single fixation duration on the target word, of the last fixation prior to the target word, the last fixation prior to the target word restricted to fixations positions at 3 or less character positions from the target word, last fixation restricted to more than three character positions away from the target word, last fixation prior to skipping the target word and the last fixation prior to landing on the target word.

\begin{tabular}{|l|c|c|c|c|c|c|}
\hline \multirow{4}{*}{} & $\begin{array}{c}\text { Target } \\
\text { word }\end{array}$ & \multicolumn{5}{|c|}{ Prior to the target word } \\
\cline { 2 - 7 } & $\begin{array}{c}\text { Single } \\
\text { fixation }\end{array}$ & Overall & $\begin{array}{c}\text { Overall } \\
\leq 3\end{array}$ & $\begin{array}{c}\text { Overall } \\
>3\end{array}$ & $\begin{array}{c}\text { Before } \\
\text { skipping }\end{array}$ & $\begin{array}{c}\text { Before } \\
\text { landing }\end{array}$ \\
\hline Predictable word & 262 & 225 & 228 & 241 & 276 & 227 \\
\hline Unpredictable word & 284 & 236 & 253 & 236 & 258 & 237 \\
\hline Sem. Anomalous word & 305 & 236 & 250 & 242 & 266 & 237 \\
\hline Visually similar non-word & 279 & 239 & 255 & 242 & 248 & 242 \\
\hline Visually dissimilar non-word & 301 & 239 & 247 & 253 & 291 & 239 \\
\hline Orth. Illegal non-word & 305 & 242 & 248 & 242 & 289 & 242 \\
\hline
\end{tabular}


Table 4. An example sentence from experiment 2 with each of the 4 parafoveal preview conditions.

1. Low foveal load - correct preview

The artist painted a brown sky which clashed with the orange flowers.

2. High foveal load - correct preview

The artist painted a lilac sky which clashed with the orange flowers.

3. Low foveal load - correct preview

The artist painted a brown sxy which clashed with the orange flowers.

4. High foveal load - incorrect preview

The artist painted a lilac sxy which clashed with the orange flowers. 
Table 5. Skipping probabilities as a function of preview and foveal load. Skipping probabilities taking regressions into account are shown in parenthesis.

\begin{tabular}{|l|c|c|}
\hline & Correct Preview & Incorrect Preview \\
\hline $\begin{array}{l}\text { High foveal load - } \\
\text { Low frequent word }\end{array}$ & $.40(.28)$ & $.25(.14)$ \\
\hline $\begin{array}{l}\text { Low foveal load - } \\
\text { High frequent word }\end{array}$ & $.45(.37)$ & $.37(.24)$ \\
\hline
\end{tabular}


Table 6. Fixation times (ms) on the word prior to the target word and on the target word.

\begin{tabular}{|l|c|c|c|c|}
\hline \multirow{2}{*}{} & \multicolumn{2}{|c|}{$\begin{array}{c}\text { Single fixation times } \\
\text { Prior word }\end{array}$} & \multicolumn{2}{c|}{$\begin{array}{c}\text { Single fixation times } \\
\text { Target }\end{array}$} \\
\cline { 2 - 5 } & $\begin{array}{c}\text { Correct } \\
\text { Preview }\end{array}$ & $\begin{array}{c}\text { Incorrect } \\
\text { Preview }\end{array}$ & $\begin{array}{c}\text { Correct } \\
\text { Preview }\end{array}$ & $\begin{array}{c}\text { Incorrect } \\
\text { Preview }\end{array}$ \\
\hline $\begin{array}{l}\text { High foveal load - } \\
\text { Low frequent word }\end{array}$ & 315 & 310 & 296 & 333 \\
\hline $\begin{array}{l}\text { Low foveal load - } \\
\text { High frequent word }\end{array}$ & 278 & 293 & 266 & 306 \\
\hline
\end{tabular}


Table 7. Skipping probabilities of the $\mathbf{1 0}$ fastest and slowest readers as a function of preview and foveal load. Skipping probabilities taking regressions into account are shown in parenthesis.

\begin{tabular}{|l|c|c|c|c|}
\hline \multirow{2}{*}{} & \multicolumn{2}{|c|}{10 fastest readers } & \multicolumn{2}{c|}{10 slowest readers } \\
\cline { 2 - 5 } & $\begin{array}{c}\text { Correct } \\
\text { Preview }\end{array}$ & $\begin{array}{c}\text { Incorrect } \\
\text { Preview }\end{array}$ & $\begin{array}{c}\text { Correct } \\
\text { Preview }\end{array}$ & $\begin{array}{c}\text { Incorrect } \\
\text { Preview }\end{array}$ \\
\hline $\begin{array}{l}\text { High foveal load - } \\
\text { Low frequent word }\end{array}$ & $.57(.36)$ & $.38(.18)$ & $.23(.19)$ & $.12(.09)$ \\
\hline $\begin{array}{l}\text { Low foveal load - } \\
\text { High frequent word }\end{array}$ & $.63(.49)$ & $.50(.32)$ & $.27(.24)$ & $.23(.17)$ \\
\hline
\end{tabular}

